\title{
Pemahaman Siswa tentang Budaya Politik dan Kesadaran Berdemokrasi dengan Komitmen Berakhlakul Kharimah
}

\author{
Budi Waluyo $^{1 *}$, Sri Rahayu Pudjiastuti ${ }^{2}$, Mohamad Sutisna ${ }^{2}$ \\ ${ }^{\text {I}}$ SMK Citra Mutiara, Indonesia \\ ${ }^{2}$ STKIP Arrahmaniyah, Indonesia
}

\begin{abstract}
Abstrak - Akhlakul karimah tidak lahir begitu saja menjadi kodrat manusia atau muncul secara tiba-tiba. Akan tetapi membutuhkan proses yang panjang serta memanifestasi seumur hidup melalui pembelajaran atau pendidikan akhlak yang sistematis bersifat menyeluruh meliputi 4 dimensi kehidupan manusia yaitu fisik, mental, emosional dan spiritual. Penelitian bertujuan untuk mengetahui Hubungan pemahaman budaya politik dan kesadaran berdemokrasi dengan komitmen berakhlakul karimah. Metode penelitian menggunakan metode kuantitatif dengan teknik korelasional. Populasi dalam penelitian adalah siswa kelas XI di SMK Kecamatan Serang Baru Bekasi berjumlah 139 siswa yang berada di 5 Sekolah. Untuk sampel digunakan teknik proportional random sampling dengan rumus Slovin, sehingga diperoleh sampel sebanyak 103 orang siswa. Untuk ujicoba instrumen diambil sebanyak 30 orang. Hasil penelitian menunjukkan: Terdapat hubungan positif pemahaman budaya politik dan kesadaran berdemokrasi secara bersama-sama dengan komitmen berakhlakul karimah dengan koefisien korelasi $\mathrm{R}$ sebesar 0,803 dan persamaan regresi berganda $\hat{Y}=42,84+0,46 X_{1}+0,32 X_{2}$ dan harga $F_{\text {hitung }}=91,026>3,09=F_{\text {tabel }}$ pada taraf signifikansi $\alpha=0,05$. Hipotesis nol ditolak dan hipotesis penelitian diterima pada taraf signifikansi 0,05. Kesimpulan dari penelitian ini adalah: Terdapat hubungan positif pemahaman budaya politik dan kesadaran berdemokrasi secara bersama-sama dengan komitmen berakhlakul karimah pada siswa SMK di Kecamatan Serang Baru Kabupaten
\end{abstract} Bekasi.

\author{
Kata kunci: \\ Budaya Politik, \\ Kesadaran Berdemokrasi, \\ Akhlakul Kharimah.
}

\section{Histori:}

Dikirim: 10 Maret 2021

Direvisi: 15 Maret 2021

Diterima: 17 Maret 2021

Online: 18 Maret 2021

\section{Identitas Artikel:}

Waluyo, B., Pudjiastuti, S. R., \& Sutisna, M. (2021). Pemahaman Siswa tentang Budaya Politik dan Kesadaran Berdemokrasi dengan Komitmen Berakhlakul Kharimah. Jurnal Citizenship Virtues, 1(1), 51-56.

\section{PENDAHULUAN}

Akhlak adalah bentuk perilaku makhluk dalam berhubungan baik kepada khaliknya atau kepada sesama (Ghazali, 1991). Komitmen adalah kondisi psikologis yang menunjukkan kehendak serius melakukan tindakan (Odiorne, 1990). Komitmen ini didasarkan kepada hadits Rasulullah SAW, yaitu "khairunnaas anfa'uhum

\footnotetext{
*Corresponding author

E-mail: rizkaoktavia0210@gmail.com
} 
linnaas" (sebaik-baik manusia adalah yang banyak memberikan manfaat bagi orang lain). Pada dasarnya nilai-nilai akhlakul karimah yang dibawa oleh Islam, jika diamalkan secara konsisten dan penuh rasa tanggung jawab mampu menjawab problematika yang sedang diderita umat Islam saat ini, terutama dalam permasalahan budaya politik dan kesadaran berdemokrasi. Budaya politik (political culture) hampir bisa dipastikan adalah aspek reformasi politik yang tidak berkembang signifikan sepanjang masa transisi dan konsolidasi demokrasi Indonesia selama dua dasawarsa terakhir. Demokrasi Pancasila bukanlah demokrasi yang berdasarkan kekuatan mayoritas (Harefa \& Fatolosa Hulu, 2020), karena setiap golongan tidak boleh memaksakan kehendaknya kepada golongan lain. Demokrasi Pancasila bukan terletak pada seseorang yang berpengaruh terhadap orang banyak yang dapat mengambil keputusan berdasarkan kemauan sendiri (Alwan \& Warsono, 2021). Kesadaran berdemokrasi memberikan kesempatan pada seseorang untuk menyatakan pendapatnya dan boleh membuat keputusan yang diinginkan di dalam melaksanakan sesuatu namun keputusan yang diambil harus mendapatkan persetujuan berdasarkan mufakat (Budiardjo, 2000).

Siswa pada umumnya hanya mampu memahami pengertian budaya politik dan sikap demokrasi akan tetapi belum mampu untuk mendeskripsikanya. Hasil belajar siswa tentang budaya politik hanya sebatas mengukur kemampuan siswa secara kognitif, afektif dan psikomotor, dengan indikator; (1) pengertian budaya politik, (2) macam-macam budaya politik, (3) partisipasi politik, (4) fungsi partai politik, (5) implementasi budaya politik (Abidin, 2020).

Pudjiastuti (2020a) menjelaskan implementasi nilai-nilai Pancasila bagi generasi milenial yang terintegrasi dalam kurikulum pendidikan dengan menekankan aspek praktek, tidak kognitif semata, mengikutsertakan semua stakeholder yang ada. Mengenalkan kearifan local mulai dari cerita rakyat, kesenian tradisional, hingga permainan tradisional. Selanjutnya Pudjiastuti (2020b) menjelaskan bahwa cara yang dapat dilakukan untuk menginternalisasikan nilainilai luhur Pancasila adalah; memperkuat sistem pendidikan, meningkatkan identitas diri dan karakter bangsa, pemimpin nasional memiliki komitmen yang tinggi, mengimplementasikan nilai-nilai Pancasila dalam kehidupan nyata agar memiliki kemampuan untuk menangkal pengaruh negatif. Paradigma orang yang berakhlakul karimah jauh lebih baik dari pada orang yang berpendidikan tinggi, karena fundamental dari sebuah pendidikan adalah akhlakul karimah (Azis \& Ruslan, 2021).

\section{METODE PENELITIAN}

Metode penelitian yang digunakan adalah metude kuantitatif dengan pendekatan korelasional. Ary, Jacobs, Irvine \& Walker (2018) menyatakan bahwa penelitian korelasional merupakan bagian dari metode survei dirancang untuk memperoleh informasi tentang status gejala pada saat penelitian dilakukan. metode survei digunakan bukan saja untuk membandingkan kondisi-kondisi tersebut dengan kriteria yang telah ditetapkan sebelumnya atau untuk menilai keefektifan program, melainkan survei dapat juga digunakan untuk menyelidiki hubungan atau untuk menguji hipotesis (Pudjiastuti, 2017). Populasi dalam penelitian ini adalah seluruh siswa SMK Kecamatan Serang Baru Kabupaten Bekasi sebanyak 3.164 siswa, sedangkan populasi terjangkau siswa Kelas XI sebanyak 1139 orang siswa yang 
berada di 5 Sekolah, yaitu SMK Citra Mutiara, SMK Darma Asih, SMK Armaniah, SMK Abdi Negara dan SMK Almanar, untuk menentukan jumlah sampel 103 orang siswa digunakan teknik proportional random sampling.

Penelitian ini dilaksanakan pada bulan Juli sampai Oktober 2019. Instrumen yang dipakai untuk mengukur variabel pemahaman budaya politik menggunakan tes, untuk variable kesadaran berdemokrasi menggunakan angket skala sikap, sedangkan variabel komitmen berakhlakul kharimah menggunakan angket skala perilaku. Keseluruhan instrument telah diuji coba tingkat validitas dan reliabilitasnya pada taraf signifikansi 0,95 atau 0,05\%. Pengujian hipotesis dilakukan dengan korelasi Product Moment (Pudjiastuti, 2019).

\section{HASIL DAN PEMBAHASAN}

\section{Hubungan Pemahaman Siswa Tentang Budaya Politik $\left(\mathbf{X}_{1}\right)$ dengan Komitmen Berakhlakul Karimah (Y)}

Perhitungan korelasi sederhana terhadap pasangan data variabel pemahaman siswa tentang budaya politik $\left(\mathrm{X}_{1}\right)$ dengan variabel komitmen berakhlakul karimah $(\mathrm{Y})$, menghasilkan harga koefisien korelasi $r_{y 1}$ sebesar 0,776. Angka ini mengisyaratkan bahwa hubungan pemahaman siswa tentang budaya politik dengan variabel komitmen berakhlakul karimah adalah positif. Hasil analisis uji- $t$ diperoleh besaran $t_{\text {hitung }}$ sebesar 12,364. Jika besaran ini dikonsultasikan dengan besaran $t_{\text {tabel }}(0.05)$ diperoleh besaran sebesar 1,658 yang menunjukkan bahwa koefisien korelasi antara pemahaman siswa tentang budaya politik (variabel $\mathrm{X}_{1}$ ) dengan komitmen berakhlakul karimah (variabel $\mathrm{Y}$ ) sangat signifikansi. Kekuatan hubungan pemahaman siswa tentang budaya politik (variabel $\mathrm{X}_{1}$ ) dengan komitmen berakhlakul karimah (variabel Y) dapat diketahui dari hasil perhitungan koefisien determinasinya. Besaran koefisien determinasi tersebut adalah sebesar 0,602. Besaran ini memberikan pengertian bahwa 60,2\% varians pemahaman siswa tentang budaya politik dapat dijelaskan oleh varians komitmen berakhlakul karimah.

\section{Hubungan Kesadaran Berdemokrasi $\left(\mathrm{X}_{2}\right)$ dengan Komitmen Berakhlakul Karimah (Y)}

Perhitungan korelasi sederhana terhadap pasangan data variabel kesadaran berdemokrasi $\left(\mathrm{X}_{2}\right)$ dengan variabel komitmen berakhlakul karimah (Y), menghasilkan harga koefisien korelasi $r_{\mathrm{y} 2}$ sebesar 0,718. Angka ini mengisyaratkan bahwa hubungan kesadaran berdemokrasi dengan komitmen berakhlakul karimah adalah positif. Untuk mengetahui apakah koefisien korelasi $r_{\mathrm{y} 2}$ yang diperoleh signifikan atau tidak, dilakukan pengujian dengan menggunakan analisis uji-t. Hasil analisis uji- $t$ diperoleh besaran $t_{\text {hitung }}$ sebesar 10,366. Jika besaran ini dikonsultasikan dengan besaran $t_{\text {tabel (0.05) }}$ diperoleh besaran sebesar 1,658 yang menunjukkan bahwa koefisien korelasi antara kesadaran berdemokrasi (variabel $\mathrm{X}_{2}$ ) dengan komitmen berakhlakul karimah (variabel $\mathrm{Y}$ ) sangat signifikan. Kekuatan hubungan kesadaran berdemokrasi (variabel $\mathrm{X}_{2}$ ) dengan komitmen berakhlakul karimah siswa (variabel Y) dapat diketahui dari hasil perhitungan koefisien determinasinya. Besaran koefisien determinasi tersebut adalah sebesar 0,515. Besaran ini memberikan pengertian bahwa 51,5\% varians komitmen berakhlakul karimah dapat dijelaskan oleh varians kesadaran berdemokrasi. 


\section{Hubungan Pemahaman siswa Tentang Budaya Politik $\left(X_{1}\right)$ dan Kesadaran Berdemokrasi $\left(\mathbf{X}_{2}\right)$ Secara Bersama-sama dengan Komitmen Berakhlakul $\operatorname{Karimah}(\mathbf{Y})$}

Untuk mengetahui apakah koefisien korelasi $\mathrm{R}$ yang diperoleh signifikan atau tidak, dapat di uji dengan menggunakan uji- $F$. Hasil analisis uji- $F$ diperoleh besaran sebesar 91,026. Besaran ini dikonsultasikan dengan besaran $F_{\text {tabel (0.05) }}$ diperoleh besaran sebesar 3,09 yang menunjukkan bahwa koefisien korelasi antara pemahaman siswa tentang budaya politik dan kesadaran beribadah secara bersamasama dengan komitmen berakhlakul karimah sangat signifikan. Dengan demikian hipotesis ketiga yang menyatakan terdapat hubungan positif pemahaman siswa tentang budaya politik dan kesadaran berdemokrasi secara bersama-sama dengan komitmen berakhlakul karimah siswa diterima dan hasil pengujian dapat dinyatakan signifikan. Untuk mengetahui besarnya sumbangan variabel pemahaman siswa tentang budaya politik dan kesadaran berdemokrasi dengan komitmen berakhlakul karimah siswa dapat dilakukan dengan mengkuadratkan besaran koefisien korelasi. Hasil pengkuadratan besaran tersebut diperoleh besaran sebesar 0,645. Dengan demikian dapat disimpulkan bahwa besarnya sumbangan pemahaman siswa tentang budaya politik dan kesadaran berdemokrasi secara bersama-sama komitmen berakhlakul karimah siswa adalah 64,5\%, dalam arti bahwa 35,5\% lainnya dipengaruhi oleh variabel lain yang tidak diamati dalam penelitian ini.

Untuk melihat hubungan salah satu variabel bebas dengan variabel terikat dalam kondisi variabel bebas lainnya dikontrol (tetap), dilakukan analisis korelasi parsial. Analisis korelasi parsial dilakukan antara variabel $\mathrm{Y}$ dengan variabel $\mathrm{X}_{1}$ dalam kondisi variabel $\mathrm{X}_{2}$ dikontrol (tetap). Hasil perhitungan memperoleh besaran $r_{y 1.2}$ sebesar 0,518. Uji signifikansi koefisien korelasi parsial $r_{y 1.2}$ menggunakan statistik uji- $t$ dan memperoleh hasil $t_{\text {hitung }}=6,086$. Besaran ini dikonsultasikan dengan $t_{\text {tabel }}$ dalam taraf nyata alpha 0,05 ; diperoleh besaran $t$ sebesar 1,658 atau $t_{\text {hitung }}>t_{\text {tabel }}$. Dengan demikian koefisien korelasi parsial $r_{y 1.2}$ dapat dinyatakan sangat signifikan. Analisis korelasi parsial dilakukan antara variabel $\mathrm{Y}$ dengan variabel $\mathrm{X}_{2}$ dalam kondisi variabel $\mathrm{X}_{1}$ dikontrol (tetap). Hasil perhitungan memperoleh besaran $r_{y 2.1}$ sebesar 0,330. Uji signifikansi koefisien korelasi parsial $r_{y 2.1}$ menggunakan statistik

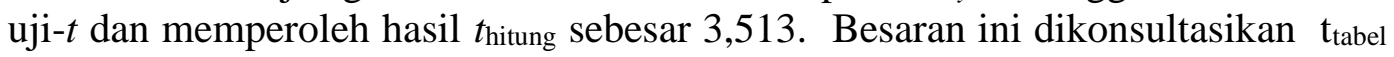
dalam taraf nyata alpha 0,05 ; diperoleh besaran $t$ sebesar 1,658 atau $t_{\text {hitung }}>t_{\text {tabel }}$. Dengan demikian koefisien korelasi parsial $r_{y 2.1}$ dapat dinyatakan sangat signifikan.

\section{KESIMPULAN}

Hasil pengujian hipotesis menunjukkan bahwa ketiga hipotesis alternatif $\left(\mathrm{H}_{\mathrm{a}}\right)$ yang diajukan dalam penelitian ini diterima, dan menolak hipotesis nol $\left(\mathrm{H}_{0}\right)$. Dengan demikian berarti terdapat hubungan positif: (1) pemahaman siswa tentang budaya politk dengan komitmen berakhlakul karimah, (2) kesadaran berdemokrasi dengan komitmen berakhlakul karimah, (3) pemahaman siswa tentang budaya politk dan kesadaran berdemokrasi secara bersama-sama dengan komitmen berakhlakul karimah. Hasil uji- $t$ untuk hipotesis pertama dan hipotesis kedua, serta hasil uji $F$ untuk hipotesis ketiga menunjukkan bahwa ternyata pengaruh tersebut sangat signifikan, baik pada taraf signifikansi alpha 0,05 maupun pada taraf signifikansi 
alpha 0,01 . Berdasarkan uraian tersebut maka beberapa kesimpulan penelitian dapat dirumuskan sebagai berikut:

Pertama, terdapat hubungan positif pemahaman siswa tentang budaya politik dengan komitmen berakhlakul karimah pada siswa SMK di Kecamatan Serang Baru Kabupaten Bekasi. Ini berarti bahwa makin tinggi pemahaman siswa tentang budaya politik, makin tinggi pula komitmen berakhlakul karimah siswa tersebut. Demikian pula sebaliknya, makin rendah pemahaman siswa tentang budaya politik, makin rendah pula komitmen berakhlakul karimah siswa tersebut. Oleh karena itu pemahaman siswa tentang budaya politik merupakan variabel yang penting untuk diperhatikan di dalam memprediksi komitmen berakhlakul karimah.

Kedua, terdapat hubungan positif kesadaran berdemokrasi dengan komitmen berakhlakul karimah siswa SMK di Kecamatan Serang Baru Kabupaten Bekasi. Ini berarti bahwa makin tinggi kesadaran berdemokrasi seorang siswa akan makin tinggi komitmen berakhlakul karimah tersebut. Demikian pula sebaliknya, makin rendah kesadaran berdemokrasi siswa, makin rendah pula komitmen berakhlakul karimah siswa tersebut. Oleh karena itu kesadaran berdemokrasi merupakan variabel yang penting untuk diperhatikan di dalam memprediksi komitmen berakhlakul karimah siswa.

Ketiga, terdapat hubungan positif pemahaman siswa tentang budaya politik dan kesadaran berdemokrasi secara bersama-sama dengan komitmen berakhlakul karimah siswa SMK di Kecamatan Serang Baru Kabupaten Bekasi. Dengan demikian berarti bahwa makin tinggi pemahaman siswa tentang budaya politik dan makin tinggikesadaran berdemokrasinya, makin tinggi pula komitmen berakhlakul karimah siswa tersebut. Demikian pula sebaliknya, makin rendah pemahaman siswa tentang budaya politik dan makin rendah kesadaran berdemokrasinya, makin rendah pula komitmen berakhlakul karimah siswa tersebut. Kondisi ini menunjukkan bahwa pemahaman siswa tentang budaya politik dan kesadaran berdemokrasi, merupakan dua variabel yang penting untuk diperhatikan dalam menjelaskan peningkatan komitmen berakhlakul karimah.

\section{REFERENSI}

Abidin, A. (2020). Meningkatkan Hasil Belajar Tentang Budaya Politik Dan Sikap Demokrasi Melalui Metode Problem Solving. Sintesa: Jurnal Ilmu Pendidikan, 15(1), 58-66.

Alwan, M. Z., \& Warsono, W. (2021). Penerapan Demokrasi Pancasila dalam Proses Pemilihan Ketua Umum Himnas PPKn pada Kongres dan Rakernas di Universitas Negeri Yogyakarta Tahun 2018. Kajian Moral dan Kewarganegaraan, 9(1), 218-232.

Ary, D., Jacobs, L. C., Irvine, C. K. S., \& Walker, D. (2018). Introduction to research in education. Mason, $\mathrm{OH}$ : Cengage Learning.

Azis, M. R., \& Ruslan, R. (2021). Upaya Menanamkan Akhlakul Karimah Siswa Dalam Pembelajaran PAI di Era Milenial. Al-Ulum Jurnal Pemikiran dan Penelitian ke Islaman, 8(1), 128-138.

Budiardjo, M. (2000). Dasar-Dasar Ilmu Politik. Jakarta. Gramedia Pustaka Utama.

Ghazali, A. I. (1991). Ihya" Ulumuddin, asy-Syifa". Semarang: CV Asy Syifa. 
Harefa, D., \& Fatolosa Hulu, M. M. (2020). Demokrasi Pancasila di Era Kemajemukan. Banyumas: PM Publisher.

Odiorne, G. S. (1990). The human side of management. San Diego California: Lexington Books.

Pudjiastuti, S. R. (2017). Metode Penelitian Pendidikan. Depok: Fatma Aji.

Pudjiastuti, S. R. (2019). Penelitian Pendidikan. Yogyakarta: Media Akademi.

Pudjiastuti, S. R. (2020a). Implementasi Nilai-Nilai Pancasila bagi Generasi Milenial. In Tim Asosiasi Dosen Pancasila dan Kewarganegaraan. Implementasi Nilai-Nila Pancasila Di Era 4.0, pp. 65-88. Depok: Gemala.

Pudjiastuti, S. R. (2020b). Internalisasi Nilai-Nilai Pancasila Dalam Mencegah Paham Radikal. Jurnal Ilmiah Mimbar Demokrasi, 19(2), 32-39. 